\title{
An improved coordination between GPs and Psychiatrists helps provide faster attention to mental health patients
}

\author{
Rajaram Govindarajan"*, Joan Ribas Sabaté2, Alexis Andreu Gracia², Mar Rus Calafell², Aurora Garriga Badia ${ }^{4}$, Lídia Ugas Ballester ${ }^{5}$, Mar \\ Casanovas Marfà ${ }^{6}$ and Daniel Vega Moreno ${ }^{2,3}$ \\ ${ }^{1}$ Independent Hospital Management Consultant and Management Professor of the Department of Operations Management, Innovation and Data Sciences, \\ ESADE Business School, Barcelona, Spain \\ ${ }^{2}$ Salut Mental, Consorci Sanitari de l'Anoia, Igualada, Barcelona, Spain \\ ${ }^{3}$ Unitat de Psicologia Mèdica, Departament de Psiquiatria i Medicina Legal \& Institut de Neurociències, Universitat Autònoma de Barcelona, Spain \\ ${ }^{4}$ Atenció Primària. Consorci Sanitari de l'Anoia, Igualada, Barcelona, Spain \\ ${ }^{5}$ Benito Menni CASM HHSCJ. Granollers. Barcelona, Spain \\ ${ }^{6}$ Farmacia, SAP Anoia. Institut Català de la Salut. Igualada. Barcelona, Spain
}

\begin{abstract}
Before implementing the Program of Support to Primary Health Care (PSP) - for people over the age of 18 - in our region (meaning before the complete deployment of the program to all primary health care centers) we carried out a pilot study in one of these Basic Healthcare Zones locally known as ABS zones. This trial lasted one semester and its main purpose was to validate the results derived from the application of the program and to evaluate the degree of satisfaction of the involved primary health care professionals. This paper presents the results of this pilot trial.
\end{abstract}

\section{Introduction}

According to the WHO (2002), psychiatric and neurological disorders account for $39.7 \%$ of the years of life lived with a disability in Europe. In 2008, the World Health Organization (WHO) predicted the need for a better integration between mental health care services and primary health care services (WHO, 2008) in order to improve access to proper treatment.

The Program of Support to Primary Health Care (PSP) for people over the age of 18 originated in the Generalitat of Catalonia's Pla director de Salut Mental i Addiccions de la Generalitat de Catalunya (Master Plan for Mental Health and Addictions of the Generalitat of Catalonia), and was deployed in our region beginning in 2009. The objectives of PSP are the creation of a portfolio of mental health and primary health care services, the improvement of health care professional training, increasing the level of assistance given to primary health care professionals by those working in the field of mental health care, as well as the early detection of mental health problems within the context of primary health care scenarios.

These objectives translate into the following concrete measures:

- Improving the coordination between teams of mental health care professionals for adults and primary health care professionals.

- Improving early detection of and care for people with serious mental disorders.

- Shortening the waiting list and waiting time for first consultations.

- Lowering the demand on mental health care services for visits by patients without severe mental disorders.

- Participation in mental health care training by primary health care professionals.
- Improving mental health care treatment in the region.

In terms of programs for case and disease management, the basic premise of all projects is that a more assertive management of medical interventions, by means of the implementation of better clinical practices throughout the course of illnesses, should improve the population's overall heath and quality of life (furthermore, patients can acquire the skills and knowledge needed to confront their illness). This method can help to lower inappropriate demand on services as well as their inadequate use, leading to a reduction in costs. To this end, some projects advocate an improvement in the coordination between different levels of healthcare services [1-3] others suggest that liaison consultations, in addition to referring patients to specialized mental health services, result in a decreased waiting time for specialized first consultations (Haggarty et al, 2012) and improved care for service users with more serious mental pathologies $[4,5]$.

\section{Materials and Methods}

The region of Anoia, whose capital is Igualada, is in the province of Barcelona. It is the geo-demographic region of reference with a population of 89,894 inhabitants older than 17 years of age (according to 2011 statistics), half of whom reside in the urban center comprised

Correspondence to: Rajaram Govindarajan, Independent Hospital Management Consultant and Management Professor of the Department of Operations Management, Innovation and Data Sciences, ESADE Business School, Barcelona, Spain, Tel: +34 666763 348; E-mail: rajaram@spgcertificacion.com

Key words: Mental health, psychiatry, psychology, primary health care, coordination, activity results, satisfaction

Received: October 13, 2017; Accepted: September 16, 2017; Published: September 18, 2017 
of the municipalities of Conca d'Òdena (Igualada, Vilanova and Santa Margarida), which have primarily industrial economic activities. The other half resides in towns in the region whose economic activity is mainly agricultural. It is one of the most depressed regions in Catalonia, with a high rate of unemployment.

At the time the pilot study was undertaken, the region counted 8 Basic Healthcare Zones (ABS). Before implementing the PSP in our region, we undertook a pilot study of our program for one of the ABSs (ABS-3), with the intention of validating the results garnered from the implementation of our program before deploying the program to all of the region's primary health care centers. Another ABS (ABS-8) behaved as a "blind" control, that is to say, the same psychologist who was treating patients in ABS-3, where the pilot study was being carried out, also gave treatment in ABS-8, applying the same procedure and working with the same criteria, with the sole difference that the general practitioners were unaware of this fact and did not know that they were participating in the pilot study. In this way we tried to avoid any bias which may have resulted from the general practitioners being aware of their participation in the study, and as a result modifying the type of relationship and level of coordination they had with the specialist.

As an added value to the project, the mental health service transferred, on a weekly basis, a psychologist to the ABS, in such a way as to allow the psychologist to have an open agenda and to be able to carry out first consultations and follow up consultations, in addition to having the requisite time to coordinate with the general practitioners. In the particular case of ABS-3 which participated in the pilot study and of ABS-8, the psychiatrist attended a bimonthly coordination meeting.

In the area of innovation, the first step was to design an instrument which would allow us to facilitate the coordination as well as referral criteria for those cases put forward by the general practitioner (Table 1, Referral criteria for mental health care - PSP); we also needed to establish a streamlined means of communication between primary health care professionals and the referring psychologists at the ABS by means of telephone calls and/or emails.
The referral criteria were drafted more in the way of symptoms than in illnesses (with their corresponding codification following currently available handbooks) in order to facilitate the relations between professionals. Moreover, a categorization was established as a function of the severity of the symptoms, from the most banal which should be treated by the primary health care services (with adequate recommendations by specialists if need be), to the more severe symptoms which would require a referral to a mental health care center for follow up treatment.

After coordination between the two teams of professionals, and following the criteria established in the table, the patient is attended to:

1. At the ABS: the mental health specialist for adults performs a first consultation and after diagnosis, a proposal for a therapy is made and carried out at the ABS by him or herself or by the general practitioner.

2. At the CSM: the mental health specialist for adults performs a first consultation at the ABS and after diagnosis, refers the patient to the CSM, a proposal for a therapy is made and carried out at the CSM in the case of a patient a with severe mental disorder.

In order to evaluate the degree of satisfaction with the program on the part of the primary health care professionals, an ad hoc evaluation instrument was created. Anonymously, the professionals from the ABS were asked to answer 4 Likert type questions having to do with the procedural changes which had occurred since the implementation of the program:

a) "the waiting time for attending to referred patients has been reduced" (L-1);

b) "a better diagnostic of the patient is being made" (L-2);

c) "the coordination with mental health specialists has been improved" (L-3);

d) "the patients are being better treated" (L-4).

Table 1. Referral criteria for mental health care - PSP.

REFERRAL CRITERIA CHECKLIST FOR GPS

Psychiatrist:

Psychologist:

GP's contact number: $\quad$ GP's e-mail address:

\begin{tabular}{|l|l|l}
\hline SYMPTOMS \& SIGNS & EVALUATE & DO NOT REFER TO PSYCHIATRIST
\end{tabular}

PSYCHOTIC SYMPTOMS

- Hallucinations

- Suicidal ideation

- Behavioral disorders (impulsivity, self-destructive

behavior, eating disorder ...)

- AP or AF psychiatric symptoms which may qualify the current condition

SYMPTOMS OF DEPRESSION:

- History of bipolar disorder

- Recurring episodes

- Moderate or severe intensity

\section{SYMPTOMS OF ANXIETY:}

- Obsessions/compulsions

- Agoraphobic panic attack

- Functional limitation

\section{SUBSTANCE USE:}

Cocaine, opiates, cannabis, benzodiazepines EVALUATE DO NOT REFER TO PSYCHIATRIST

SYMPTOMS OF DEPRESSION:

Mild intensity: evaluate when there is no response to psycho- Related to: work or family life, organic illness, marital pharmacological treatment (6-9 weeks)

\section{SYMPTOMS OF ANXIETY:}

- Social anxiety: evaluate when it is generalized

- Panic attack: evaluate after 4 or more episodes

- Post-traumatic stress: evaluate if persistent for more than 4 months

SUBSTANCE USE:

Alcohol: evaluate if the treatment in the ABS was

unsuccessful
SYMPTOMS OF DEPRESSION:

problems, a separation, etc.

SYMPTOMS OF ANXIETY:

- Related to: work or family life, organic illness, marital problems, a separation, etc.

- Simple phobias

- Acute stress

SUBSTANCE USE:

Nicotine

OTHER:

- Mental retardation

- Mourning of less than 6 months

- Sexual conduct disorders

- Marital problems

- Chronic pain 
Lastly, a visual analog scale was added on which a grade could be indicated for the professional's general satisfaction with the program (V-1). (Table 2-6 and Figure 1 and 2). For the data analysis, descriptive and test statistics were used by means of Student's $t$ test for the comparison of averages for independent samples.

\section{Results}

To analyze the results of the pilot study conducted at ABS-3, data was obtained from the different ABSs and was compared to the results obtained during the first semester of the year preceding the study.

\section{Referrals}

At ABS-3, in the period during which the test was being conducted, 12 cases were referred to the Center for Mental Health (CSM), compared to the 74 which had been referred during the same period in the previous year. During the pilot study, 73 concertations were made, that is to say, 73 cases were evaluated at the ABS by the psychologist and, after the first consultation and in conjunction with the general practitioner, it was concluded that these patients should undergo their treatment in a primary health care environment.

It can be observed that this type of situation does not take place in the other ABSs (those which did not record any concertations) in which this type of project was not implemented, with the exception of ABS-8.

\section{Number of days to wait for a first consultation}

The fact that the psychologist, in conjunction with the primary health care team functions as a filter - helping to focus attention on the patients with more severe conditions - has resulted in a reduction in the number of days required to perform a first consultation at the CSM, which has gone from 20.84 to 17.01 in the case of consultations with psychologists and from 48.08 to 22.72 in the case of a first consultation with a psychiatrist (Table 4).

\section{Referrals to the CSM according to the severity of symptoms criterion}

We can also observe another trend: month after month, throughout the study's duration, general practitioners were referring ever fewer patients with less severe mental disorders, while the detection and referral of patients with severe mental disorders improved and while referrals of patients with mild symptoms remained constant (these are patients who may be suffering from a difficult socioeconomic situation and/or family situation, etc.) (Figure 3).

\section{Discussion}

The term "disease management" was used for the first time in the United States by the Boston Consulting Group in 1993, essentially referring to experiments carried out by the pharmaceutical industry. The "Disease Management Association of America" (DMAA) defines Disease Management as a multidisciplinary approach to the provision of medical services, for the proactive identification of populations at risk for various diseases and the implementation of management principles to the provision of medical services. The final objective of Disease Management is to offer better medical services with an optimal cost to efficiency ratio. The experiments mainly took place in the American health system and involved patients with chronic diseases such as diabetes, asthma, congestive heart failure, and showed better results in the case of depression with evidence suggesting an improved adherence to treatments and a better quality of life for the patients [6].

In this context of Disease Management, it would not have been possible to obtain these results without putting forward the objective of transitioning from a system based on and geared towards the resolution of demands and severe pathologies to a system based on the prevention of demands and the management of pathologies and chronic conditions. Furthermore, there is a new prevailing idea: that of privileging the patient over healthcare professionals and administrators and their corporate interests and limitations which include for example simultaneous consultation with primary health care professionals in conjunction with mental health care professionals [7]. Accordingly, proposals have been made for the collaboration between various levels of health care services which have facilitated the coordination between teams by the integration of mental health care specialists into primary health care service teams [8-10].

On a separate issue, the comprehensive care offered by our program is based on four elements:

1. Knowledge base: evidence-based care, outcomes research, clinical guidelines, protocols, etc.

2. A system to manage the provision of appropriate care: centered on the individual with the illness and on the continuity of his or her treatment over time without the traditional limitations imposed by institutions on medical specializations.

3. A process of continuous improvement: based on the application of the principles and methods of continuous quality improvement.

4. In terms of values, it is necessary to break from the traditional view of the mentally ill patient and to favor the implementation of a new social perspective in with the mentally ill person has the same rights and responsibilities as anyone else.

The patients implicated in this project are those who have passed through the three filters of the Goldberg model [11], and who present symptoms of a psychiatric/psychological disorder which warrant

Table 2. Number of referrals per ABS and per period. (Note: SAA: semester: previous year, SPP: semester: pilot study).

\begin{tabular}{|c|c|c|c|c|c|c|c|c|c|c|c|c|c|c|c|c|}
\hline & \multicolumn{2}{|c|}{ ABS 1} & \multicolumn{2}{|c|}{ ABS 2} & \multicolumn{2}{|c|}{ ABS 3} & \multicolumn{2}{|c|}{ ABS 4} & \multicolumn{2}{|c|}{ ABS 5} & \multicolumn{2}{|c|}{ ABS 6} & \multicolumn{2}{|c|}{ ABS 7} & \multicolumn{2}{|c|}{$\begin{array}{l}\text { ABS 8 } \\
\text { (blind) }\end{array}$} \\
\hline & SAA & SPP & SAA & SPP & SAA & SPP & SAA & SPP & SAA & SPP & SAA & SPP & SAA & SPP & SAA & SPP \\
\hline JANUARY & 3 & 3 & 2 & 1 & 15 & 1 & 3 & 9 & 3 & 0 & 1 & 1 & 10 & 3 & 5 & 4 \\
\hline FEBRUARY & 3 & 1 & 0 & 0 & 11 & 2 & 5 & 11 & 4 & 4 & 2 & 1 & 6 & 5 & 19 & 2 \\
\hline MARCH & 3 & 2 & 2 & 0 & 12 & 2 & 10 & 9 & 3 & 2 & 1 & 0 & 12 & 4 & 14 & 4 \\
\hline APRIL & 4 & 4 & 0 & 3 & 10 & 5 & 8 & 5 & 5 & 0 & 0 & 1 & 5 & 7 & 6 & 5 \\
\hline MAY & 0 & 2 & 2 & 3 & 13 & 1 & 7 & 5 & 0 & 0 & 0 & 6 & 8 & 0 & 13 & 7 \\
\hline JUNE & 1 & 1 & 0 & 2 & 13 & 1 & 9 & 10 & 1 & 5 & 0 & 4 & 5 & 1 & 10 & 4 \\
\hline $\begin{array}{c}\text { TOTAL FIRST } \\
\text { SEMESTER }\end{array}$ & 14 & 13 & 6 & 9 & 74 & 12 & 42 & 49 & 16 & 11 & 4 & 13 & 46 & 20 & 67 & 26 \\
\hline CONCERTATIONS & & & & & & 73 & & & & & & & & & & 66 \\
\hline
\end{tabular}




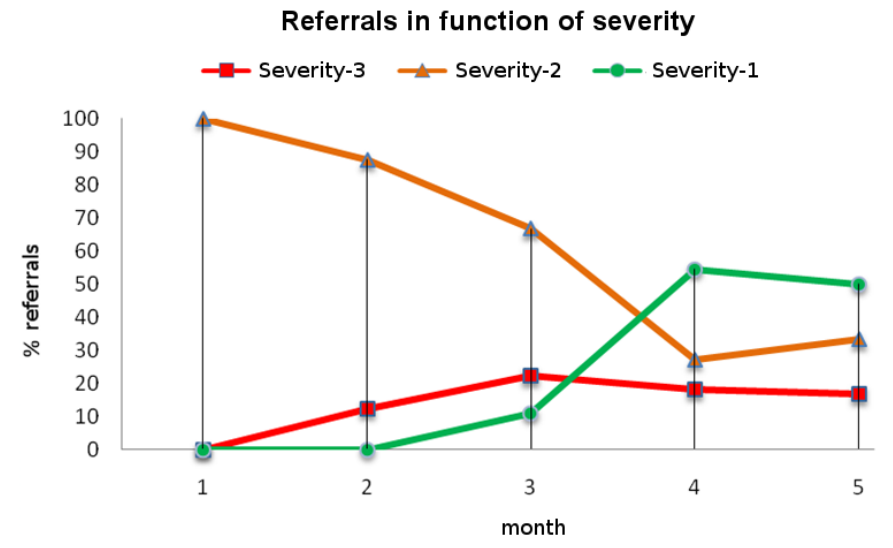

Figure 1. Percentage of referrals attended to by psychologists in function of the severity of symptoms criterion.

Table 3. Difference between average values per ABS and per period (semester of the previous year versus semester of the pilot study). ${ }^{*} \mathrm{p}<0.05 ;{ }^{* * *} \mathrm{p}<0.01$.

\begin{tabular}{|c|c|c|c|c|}
\hline & Period & $\mathbf{n}$ & Average (D.E.) & t (Gl=5) \\
\hline \multirow{2}{*}{ ABS-1 } & SAA & 14 & $2.33(1.50)$ & 0.3 \\
\hline \multirow{2}{*}{ ABS-2 } & SPP & 13 & $2.16(1.16)$ & \\
\hline \multirow{2}{*}{ ABS-3 } & SAA & 6 & $1(1.09)$ & -0.65 \\
\cline { 2 - 5 } & SPP & 9 & $1.5(1.37)$ & \\
\hline \multirow{2}{*}{ ABS-4 } & SAA & 74 & $12.33(1.75)$ & $8.06^{* *}$ \\
\hline \multirow{2}{*}{ ABS-5 } & SPP & 12 & $2(1.54)$ & \\
\cline { 2 - 5 } & SAA & 42 & $7(2.60)$ & -0.72 \\
\hline \multirow{2}{*}{ ABS-6 } & SPP & 49 & $8.16(2.56)$ & \\
\cline { 2 - 6 } & SAA & 16 & $2.66(1.86)$ & 0.66 \\
\hline \multirow{2}{*}{ ABS-7 } & SPP & 11 & $1.83(2.22)$ & -1.27 \\
\cline { 2 - 6 } & SAA & 4 & $0.66(0.81)$ & 2.56 \\
\hline \multirow{2}{*}{ ABS-8 } & SPP & 13 & $2.16(2.31)$ & $2.76^{*}$ \\
\cline { 2 - 6 } & SAA & 46 & $7.66(2.87)$ & \\
\hline
\end{tabular}

Table 4. Average for the number of days required for a first consultation at the CSM by period (semester of the previous year (SAA) versus semester of the pilot study (SPP)). ${ }^{*} \mathrm{p}<$ $0.05 ;{ }^{* *} \mathrm{p}<0.01$. SAA: Semester: previous year, SPP: Semester: pilot study.

\begin{tabular}{|c|c|c|c|}
\hline \multirow{2}{*}{ Psychiatry } & PERIOD & Average (D.E.) & t (Gl=5) \\
\hline \multirow{2}{*}{ Psychology } & SAA & $48.08(4.35)$ & $12.24^{* *}$ \\
\cline { 2 - 4 } & SPP & $22.72(6.63)$ & \\
\cline { 2 - 4 } & SAA & $20.84(3.75)$ & $2.75^{*}$ \\
\hline
\end{tabular}

their referral to specialized services. These filters are, firstly: observing the behavior of the disease, secondly: determination of the disorder, and thirdly: referral to mental health services. This referral is made following the previously explained criteria which make it essential that there be coordination between the region's various health care and social services. At the level of the first filter, the key individual is the patient (with the following associated factors: severity and type of symptoms, psychosocial stress, learned behavioral patterns for the illness, the behavior of family members, availability of medical services and the ability to pay for treatments). At the level of the second and third filters, the key individual is the primary health care physician, upon whom the following factors have an influence: knowledge of interviewing techniques, an adequate training and positive attitude allowing the physician to have confidence in his or her own capacity to manage any situation; personality factors, quality and availability of psychiatric services as well as attitudes towards psychiatrists, and finally, the patient's symptomatic pattern with its sociodemographic characteristics and the attitude of the patient towards his or her own family. Therefore, the results obtained agree with the management and clinical intervention proposals which suggest that the intervention in groups of patients based on the severity of their symptoms favors the accessibility to specialized services for those patients with the most severe disorders $[12,13]$.

This pilot study and its deployment to the rest of the region's Basic Healthcare Zones follows a tri-axial model for which none of the three axes should be overlooked and for which all three axes must be kept in balance; on the one hand, one axis is more economically focused and pragmatic (referrals, scheduled visits, recurring visits, associated pharmaceutical costs, etc.). The second axis is the one which favors creativity (action and intervention programs, etc.). The third and most essential axis is one upon which the other two rely: the axis of ethical values (improvement of patient care, families, professionals, etc.).

Lastly, and in conclusion, the implementation of the coordination program has promoted:

Table 5. Number of referrals according to severity attended to by psychologists. $1=$ =severe, specialized treatment is indicated; $2=$ uncertainty concerning the severity of the disorder and the need for specialized treatment; $3=$ mild, no specialized treatment is required.

\begin{tabular}{|c|c|c|c|c|c|}
\hline \multicolumn{5}{|c|}{ Degree of severity } \\
\hline & & $\mathbf{1}$ & $\mathbf{2}$ & $\mathbf{3}$ & \\
\hline \multirow{4}{*}{ ABS-3 } & Month & $\mathbf{N ~ ( \% )}$ & $\mathbf{N}(\%)$ & N (\%) & Total \\
\hline & February & $0(0)$ & $11(100)$ & $0(0)$ & $11(21.56)$ \\
\cline { 2 - 6 } & March & $0(0)$ & $7(87.5)$ & $1(12.5)$ & $8(15.68)$ \\
\cline { 2 - 6 } & April & $1(11.11)$ & $6(66.66)$ & $2(22.22)$ & $9(17.64)$ \\
\cline { 2 - 6 } & May & $6(54.54)$ & $3(27.27)$ & $2(18.18)$ & $11(21.56)$ \\
\cline { 2 - 6 } & June & $6(50)$ & $4(33.33)$ & $2(16.66)$ & $12(23.53)$ \\
\cline { 2 - 6 } & Total & $13(25.49)$ & $31(60.78)$ & $7(13.72)$ & \\
\hline
\end{tabular}

Table 6. Ad hoc instrument for the evaluation of the program.

\begin{tabular}{|c|c|c|c|}
\hline & & N & Average (D.E.) \\
\hline Question & L-1 & 8 & $3.75(0.7)$ \\
\hline & L-2 & 8 & $3.63(0.74)$ \\
\hline & L-3 & 8 & $4.13(0.83)$ \\
\hline & L-4 & 8 & $3.75(0.46)$ \\
\hline & V-1 & 8 & $73.75(11.87)$ \\
\hline
\end{tabular}

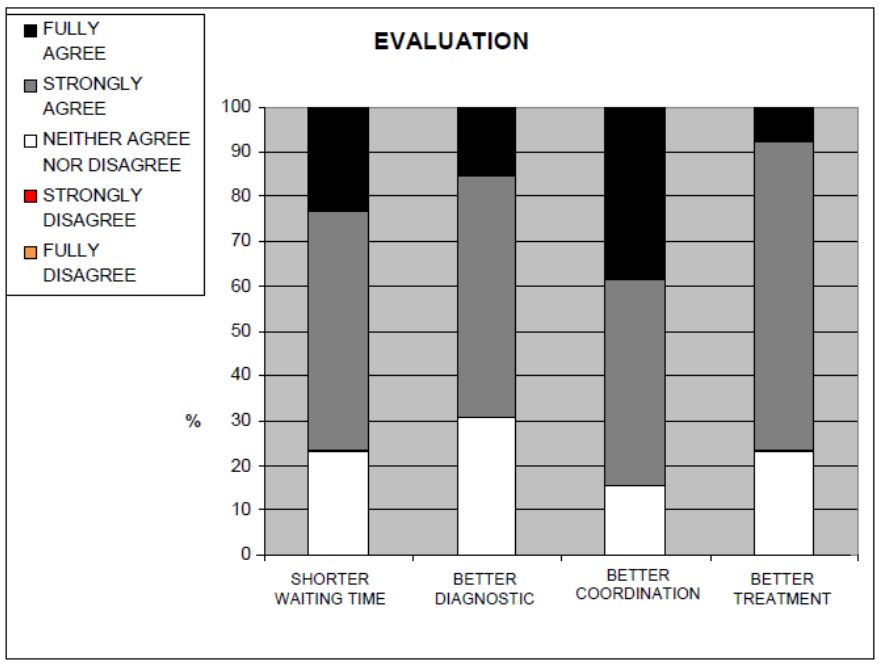

Figure 2. There are no opinions which fall into the categories "Strongly disagree" or "Fully disagree". 
AVERAGE (D.E.)

SATISFACTION GRADE (0-100)

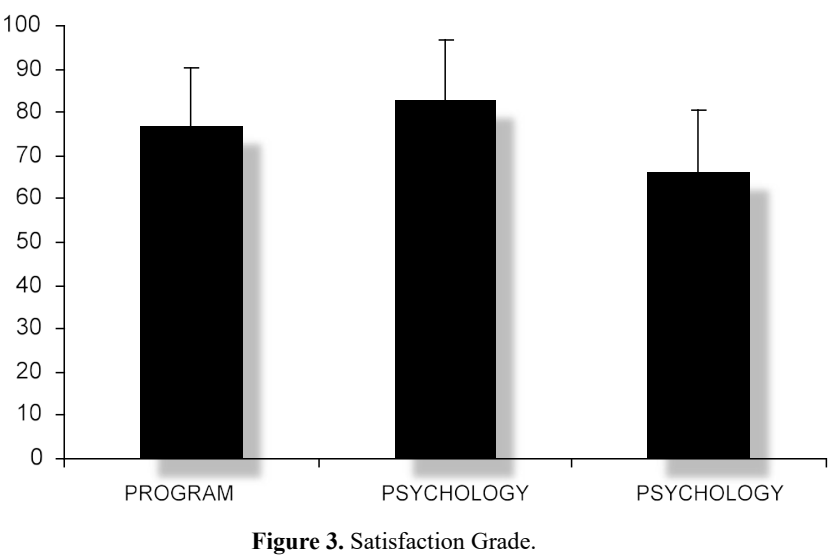

1. A better coordination between mental health care teams and primary health care teams

2. A qualitative change in patient referrals

3. A reduction in the waiting time for a patient to be attended to by specialized mental health care services

4. A high degree of perceived satisfaction on the part of the professionals working in primary health care services

5. The deployment of this pilot study to the rest of the region's Basic Healthcare Zones [14-18].

\section{References}

1. Banks R, Gask L (2008) It's time to talk: rekindling the relationship with prymary care. Advances in Psychiatric Treatment 14: 84-85.

2. Cohen A (2008) The primary care management of anxiety and depression: a GP's perspective. Advances in Psychiatric Treatment 14: 98-105.
3. Foy R, Hempel S, Rubenstein L, Suttorp M, Seeling M, et al. (2010) Meta-analysis: effect of interactive communication between collaborating primary care physicians and specialists. Annals of Internal Medicine 142: 247-258.

4. Gask L, Sibbald B, Creed T (1997) Evaluating models of working at the interface between mental health services and primary care. The British Journal of Psychiatry 170: 6-11.

5. Harrison J (2000) Prioritising referrals to a community mental health team. Br J Gen Pract 50: 194-198.

6. Mattke S, Seid M, Ma S (2007) Evidence for the effect of disease management: is \$ billion a year a good investment? Am J Manag Care 13: 670-676. [Crossref]

7. Mykletun A, Knudsen AK, Tangen T, Overland S (2010) General practitioners' opinions on how to improve treatment of mental disorders in primary health care. Interviews with one hundred Norwegian general practitioners. BMC Health Serv Res 10: 35. [Crossref]

8. Gask L, Croft J (2000) Methods of working with primary care. Advances in Psychiatric Treatment 6: 442-449.

9. Horner D, Asher K (2005) General practitioners and mental health staff sharing patient care: working model. Autralas Psychiatry 13: 176-180.

10. Kessler (2012) Mental health care treatment imitation when mental health services are incorporated into primary care practice. J Am Board Fam Med 25: 255-259.

11. Goldberg D, Huxley P (1990) Enfermedad mental en la comunidad. Ediciones Nieva. Colección: Básicos de la Psiquiatría, Madrid.

12. Hamilton R, Gordon P, Naji S (2002) Service innovation: the first year of a brief psychiatric screening clinic in primary care. The Psychiatrist 26: 218-221

13. Brady J, Mc Donnell C (2005) Service innovation: development of a primary carebased assessment service. The Psychiatrist 29: 222-224.

14. Generalitat de Catalunya (2006) Pla director de salut mental i addiccions.

15. Haggarty JM, Jarva JA, Cernovsky Z, Karioja K, Martin L (2012) Wait time impact of co-located primary care mental health services: the effect of adding collaborative care in northern Ontario. Can J Psychiatry 57: 29-33. [Crossref]

16. OMS (2002) Informe sobre la salud en el mundo 2002. Reducir los riesgos y promover una vida sana.

17. OMS (2008) Informe sobre la salud en el mundo 2008. La atención primaria de salud: Más necesaria.

18. Terol E, Hamby EF, Minue S (2001) Gestión de enfermedades (Disease management). Una aproximación integral a la provisión de cuidados sanitarios. Medifam 11: 47-54.

Copyright: (C2017 Rajaram Govindarajan. This is an open-access article distributed under the terms of the Creative Commons Attribution License, which permits unrestricted use, distribution, and reproduction in any medium, provided the original author and source are credited. 